\title{
Evaluation of Cases of Abdominal Wall Endometriosis at Universidade Estadual de Campinas in a period of 10 Years
}

\section{Avaliação dos casos de endometriose de parede abdominal na Universidade Estadual de Campinas em um período de 10 anos}

\author{
Daniela Angerame Yela ${ }^{1}$ Lucas Trigo ${ }^{1}$ Cristina Laguna Benetti-Pinto ${ }^{1}$ \\ ${ }^{1}$ Department of Obstetrics and Gynecology, Faculdade de Ciências \\ Médicas, Universidade Estadual de Campinas (Unicamp), Campinas, \\ São Paulo, Brazil \\ Rev Bras Ginecol Obstet 2017;39:403-407. \\ Address for correspondence Daniela Angerame Yela, PhD, \\ Departmento de Obstetrícia e Ginecologia, Faculdade de Ciências \\ Médicas, Universidade Estadual de Campinas - Unicamp, Rua \\ Alexander Fleming 101, 13083-970, Campinas, SP, Brazil \\ (e-mail: yela@unicamp.br).
}

\begin{abstract}
Keywords

- abdominal wall endometriosis

- pelvic pain

- recurrence

- cesarean section scar
\end{abstract}

Purpose To determine the clinical and epidemiological characteristics of abdominal wall endometriosis (AWE), as well as the rate and recurrence factors for the disease. Methods A retrospective study of 52 women with AWE was performed at Universidade Estadual de Campinas from 2004 to 2014. Of the 231 surgeries performed for the diagnosis of endometriosis, 52 women were found to have abdominal wall endometriosis (AWE). The frequencies, means and standard deviations of the clinical characteristics of these women were calculated, as well as the recurrence rate of AWE. To determine the risk factors for disease recurrence, Fisher's exact test was used.

Results The mean age of the patients was $30.71 \pm 5.91$ years. The main clinical manifestations were pain (98\%) and sensation of a mass (36.5\%). We observed that $94 \%$ of these women had undergone at least 1 cesarean section, and $73 \%$ had used medication for the postoperative control of endometriosis. The lesion was most commonly located in the cesarean section scar (65\%). The recurrence rate of the disease was of $26.9 \%$. All 14 women who had relapsed had surgical margins compromised in the previous surgery. There was no correlation between recurrent AWE and a previous cesarean section $(p=0.18)$, previous laparotomy $(p=0.11)$, previous laparoscopy $(p=0.12)$ and postoperative hormone therapy $(p=0.51)$.

Conclusion Women with previous cesarean sections with local pain or lumps should be investigated for AWE. The recurrence of AWE is high, especially when the first surgery is not appropriate and leaves compromised surgical margins.

\section{Resumo}

Objetivos Determinar as características clínicas e epidemiológicas da endometriose de parede, bem como sua taxa de recorrência e os fatores que levam a ela.

Métodos Estudo retrospectivo, em que se avaliaram 52 mulheres com endometriose de parede na Universidade Estadual de Campinas no período de 2004 a 2014. Entre as received January 21, 2017 accepted April 3, 2017 published online June 21, 2017
DOI https://doi.org/ 10.1055/s-0037-1603965. ISSN 0100-7203.
Copyright @ 2017 by Thieme Revinter

Publicações Ltda, Rio de Janeiro, Brazil
License terms

(ㄷ) (i) $\ominus$ (5) 


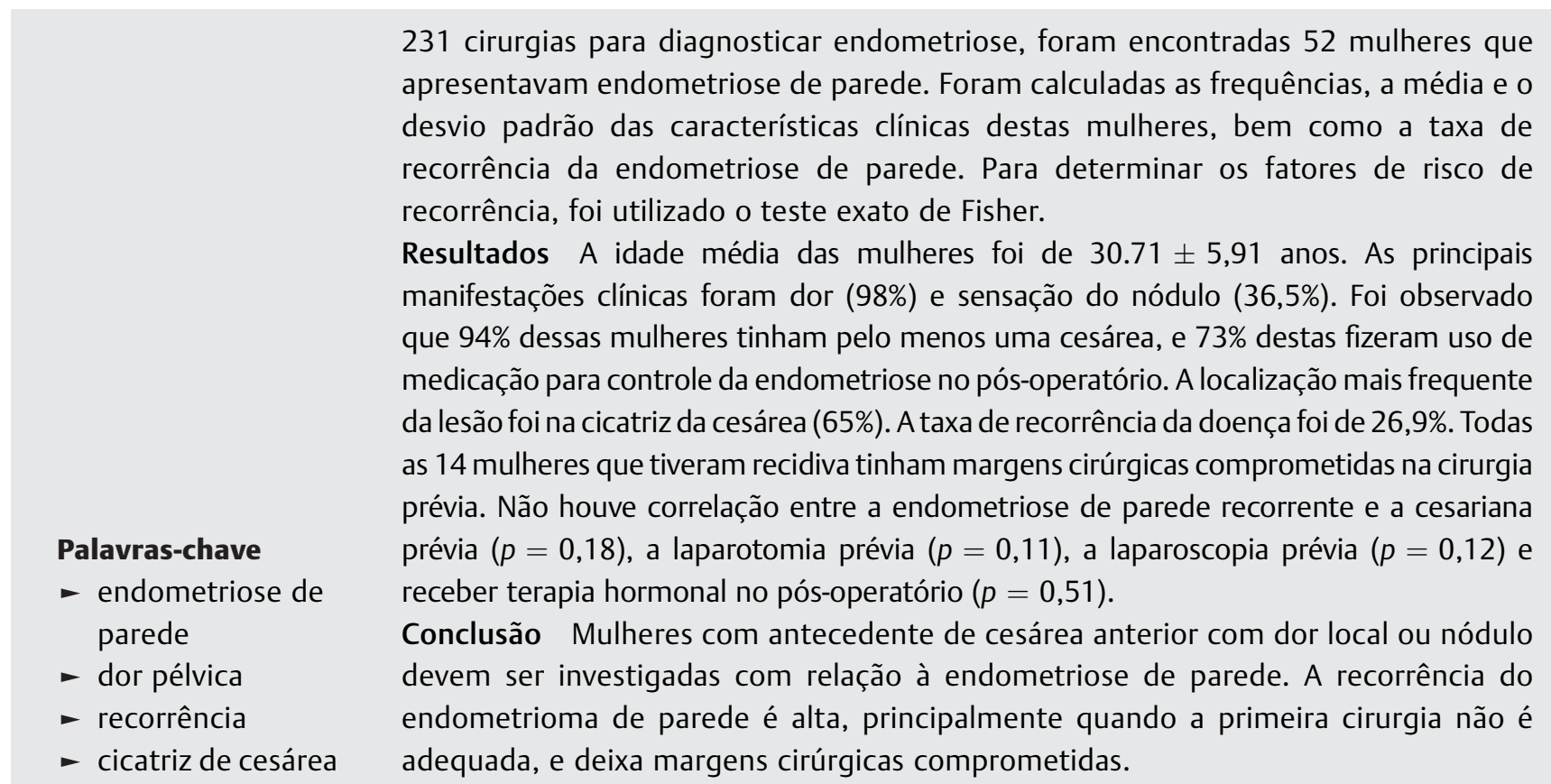

\section{Introduction}

Endometriosis is a disease characterized by the presence of endometrial tissue with glands and stroma implanted outside the uterine cavity, which responds to ovarian hormone stimulation. It is usually confined to the pelvic organs, commonly the ovaries, fallopian tubes, uterosacral ligaments, posterior cul-de-sac, rectovaginal septum and peritoneum., ${ }^{1,2}$ The disease is less commonly (9-15\%) located outside the pelvic cavity, and is termed extrapelvic endometriosis. ${ }^{3}$ The abdominal wall is the most common site for extrapelvic endometriosis. Other organs may also be affected, such as the liver, bowels, adrenal glands, lungs, kidneys, and brain. ${ }^{4-11}$

Cases of endometriosis have been described in the surgical scar, cesarean section scar, episiotomy scar after vaginal delivery, or following procedures where there was contact with endometrial tissue, such as hysterotomy performed in the first midterm of pregnancy, hysterectomy, ectopic pregnancy and tubal ligation. ${ }^{2,12,13}$ In these patients, the rate of occurrence of pelvic endometriosis is similar to that of other women, and is not regarded as a risk factor for the disease. ${ }^{14}$

The incidence of abdominal wall endometriosis (AWE) is rare. The disorder occurs in $0.03-3.5 \%$ of cases, and some studies have reported a rate of up to $12 \%{ }^{12,15}$ It is associated with a history of obstetric or gynecologic procedures, ${ }^{2,12}$ although some cases occur spontaneously. ${ }^{16}$ The disease mostly affects patients with a history of cesarean section. ${ }^{17}$ However, endometrioma has also been observed in the surgical incision following a conventional hysterectomy or laparoscopy, appendectomy and inguinal hernia. ${ }^{18}$ In these cases, the lesions, which were frequently evaluated by the general surgeon for diagnosis, were commonly misdiagnosed as hernia, hematoma, granuloma, abscess or lipoma. ${ }^{19}$
The preferential treatment is surgery, and the diagnosis is confirmed by histopathology. Other therapeutic options are the suppression of menstruation with progestins or a gonadotropin-releasing hormone (GnRH) analogue. ${ }^{20}$ In spite of the surgical removal of the lesion, there may be a recurrence rate of 1.5 to $9.1 \%$. To prevent this occurrence, surgical resection with free margins should be performed. ${ }^{20-23}$

Therefore, this study aimed at determining the clinical and epidemiological characteristics of AWE, as well as the rate of recurrence of the disease and the factors that lead to it.

\section{Methods}

A retrospective study in which 52 women with AWE were evaluated at Universidade Estadual de Campinas (Unicamp) from January 2004 to December 2014 was performed. The clinical characteristics of these women were assessed, as well as the rate of recurrence of the disease and the factors that lead to it.

The medical charts of the women undergoing surgeries described as exploratory laparotomy, exploratory laparotomy due to endometriosis, and resection of endometrioma were assessed, totaling 917 surgeries. Of the total number of surgeries, 231 were selected for the removal of endometriosis lesions. Only cases of AWE were included in the study, totaling 56 women.

Of the 56 surgeries for excision of AWE, insufficient data in the chart or lack of histopathological results that confirmed the diagnosis of endometriosis excluded another 4 cases. Therefore, 52 women remained for data analysis.

The variables analyzed were age, pregnancies, parity, cesarean section, abortion, body mass index (BMI), symptomatology of the endometrioma (pelvic pain, sensation of a 
mass, bleeding), duration of the symptomatology, associated diseases, postsurgical treatment with medication that suppressed menstruation (continuous combination estrogen/ progestin-only oral contraceptives or progestin), size and location of the endometrioma.

The study was approved by the Research Ethics Committee of the institution under number 342430/2013.

The frequencies, means and standard deviations of the clinical characteristics of the patients were calculated, as well as the recurrence rates of AWE. In order to determine the recurrence factors, Fisher's exact test was used. For the performance of these procedures, the Statistical Analysis Systems (SAS, SAS Institute, Inc., Cary, NC, US) software, version 9.4, was used.

\section{Results}

The mean age of the women was $30.71 \pm 5.91$ years. The mean BMI was $26.48 \pm 5.24 \mathrm{~kg} / \mathrm{m}^{2}$, and the main clinical manifestations were nodule pain (98\%) and the sensation of a mass (36.5\%). Only one woman had a painless mass (-Tables $\mathbf{1}, \mathbf{2}$ ).

The mean duration of the clinical treatment was $39.83 \pm 34.09$ months. Of the total number of women evaluated, $94 \%$ had undergone at least 1 cesarean section, and $73 \%$ had used medication for the control of endometriosis in the postoperative period. The lesion appeared most commonly in the cesarean section scar (65\%), and the mean size of the lesion was $2.52 \pm 1.21 \mathrm{~cm}$ on ultrasound, and $3.98 \pm 1.72 \mathrm{~cm}$ in the intraoperative period (-Table 2 ).

The recurrence rate of the disease was of $26.9 \%$. All 14 women who had relapsed had surgical margins compromised in the previous surgery. There was no correlation between recurrent AWE and a previous cesarean section $(p=0.18)$, previous laparotomy $(p=0.11)$, previous laparoscopy $(p=0.12)$ and postoperative hormone therapy $(p=0.51)$ (-Table 3$)$.

\section{Discussion}

Our results showed that the mean age of the women was 31 years. The main complaints were a palpable mass and pain at the site of the lesion. The mean duration of the symptomatology was 40 months. We observed that $94 \%$ of these patients had undergone at least 1 cesarean section. The

Table 1 Clinical characteristics of women with abdominal wall endometriosis ( $n=52$ )

\begin{tabular}{|l|l|}
\hline Women & Mean \pm SD or $\mathbf{n}(\%)$ \\
\hline Age (years) & $30.71 \pm 5.92$ \\
\hline BMI $\left(\mathrm{kg} / \mathrm{m}^{2}\right)$ & $26.48 \pm 5.24$ \\
\hline Pregnancy & $1(2)$ \\
\hline No pregnancy (0) & $51(98)$ \\
\hline Pregnancy $\geq 1$ & $49(94)$ \\
\hline Cesarean section &
\end{tabular}

Abbreviations: BMI, body mass index; SD, standard deviation.
Table 2 Characteristics of the lesions of women with abdominal wall endometriosis $(n=52)$

\begin{tabular}{|l|l|}
\hline Lesion characteristics & Mean \pm SD or $\mathbf{n}(\%)$ \\
\hline Clinical manifestations & $51(98)$ \\
\hline Nodule pain & $19(36.5)$ \\
\hline Mass & $7(13.4)$ \\
\hline Bleeding & $39.83 \pm 34.09$ \\
\hline $\begin{array}{l}\text { Duration of clinical } \\
\text { manifestations (months) }\end{array}$ & $34(65.4)$ \\
\hline Injury site & $4(7.7)$ \\
\hline Cesarean section & $14(26.9)$ \\
\hline Umbilical & $2.52 \pm 1.21$ \\
\hline Iliac fossa & $3.98 \pm 1.72$ \\
\hline $\begin{array}{l}\text { Size of endometrioma } \\
\text { in ultrasound (cm) }\end{array}$ & \\
\hline $\begin{array}{l}\text { Size of endometrioma } \\
\text { in surgery (cm) }\end{array}$ &
\end{tabular}

Abbreviation: SD, standard deviation.

predominant location of the endometriotic lesion was in the scar of the previous cesarean section, and the mean size of the lesion was $4 \mathrm{~cm}$. The diagnosis was clinical, with the aid of ultrasonography. The recurrence rate of AWE was of $26.9 \%$.

After a literature review including 445 cases of AWE, we obtained a mean patient age of 31.4 years. The main complaints were a palpable mass and pain at the site of the lesion. The majority of women had a previous cesarean section scar or some other surgical scar. The mean time between the surgery and the emergence of symptoms was 3.6 years. The recurrence rate was of $4.3 \%{ }^{24}$

Table 3 Factors associated with the recurrence of abdominal wall endometriosis $(n=14)$

\begin{tabular}{|c|c|c|c|c|}
\hline Factors & n (\%) & $p^{*}$ & RR & $95 \% \mathrm{Cl}$ \\
\hline \multicolumn{5}{|c|}{ Cesarean section } \\
\hline 0 & $2(14.3)$ & 0.18 & 0.38 & $0.15-0.97$ \\
\hline$\geq 1$ & $12(85.7)$ & & & \\
\hline \multicolumn{5}{|c|}{ Treatment } \\
\hline No & $4(28.6)$ & 0,51 & 1.55 & $0.57-4.21$ \\
\hline Yes & $10(71.4)$ & & & \\
\hline \multicolumn{5}{|c|}{ Laparotomy } \\
\hline No & $9(64.2)$ & 0.11 & 2.22 & $0.95-5.17$ \\
\hline Yes & $5(25.19)$ & & & \\
\hline \multicolumn{5}{|c|}{ Laparoscopy } \\
\hline No & $11(78.5)$ & 0.12 & 2.45 & $1.01-5.92$ \\
\hline Yes & $3(21.5)$ & & & \\
\hline
\end{tabular}

Abbreviations: $95 \% \mathrm{Cl}, 95 \%$ confidence interval; RR, relative risk. Note: *Fisher's exact test. 
A study evaluating 527 cases of endometriosis in Istanbul also obtained similar results. The mean patient age was 33 years. All patients had a history of at least one pregnancy, a previous surgical procedure, and $90 \%$ of these women had undergone a cesarean section. The predominant symptomatology was also a palpable mass and pain. The mean duration of the symptomatology was 18 months. The main location of the lesions was in the surgical scar in $84.7 \%$ of cases, and the mean size of the lesion was $4.6 \mathrm{~cm}$. The diagnosis was clinical, with the aid of ultrasonography. The recurrence rate was of $9.1 \%{ }^{2}$

Another study with 227 patients was conducted in China. The mean patient age was 32 years. All women had undergone a previous surgery, childbirth, and 99.6\% (226 patients) reported a history of cesarean section. The main imaging modality used for the preoperative diagnosis was ultrasonography. The major complaints were a palpable mass and pain. The mean duration of the symptomatology was 28 months. All lesions were in the surgical scar, with recurrence rates of $7.14 \%{ }^{21}$

According to the literature, endometriosis affects women of reproductive age. It is more common in multiparous women aged 25 to 35 years. ${ }^{25}$ Our results are similar to those of other studies. The mean age of our patients was 31 years, and $94 \%$ of these women had a history of at least 1 cesarean section. This data was also present in some studies as a risk factor for the development of AWE. ${ }^{20,26,27}$ A thorough follow-up and detailed investigation of the women of reproductive age with pelvic pain is important for better disease control and improvement in the patients' quality of life. Since many cases of AWE are evaluated by physicians other than gynecologists, the differential diagnosis should be kept in mind, when a woman of reproductive age complains of pain or a mass adjacent to a surgical scar, particularly in cases of previous childbirth or hysterotomy.

A study indicated that alcohol consumption and heavy menstrual bleeding may be risk factors for the development of AWE. In contrast, multiparity may be a protective factor. ${ }^{27}$ Cesarean section indicated after the onset of contractions also seems to offer protection against the disease, compared with elective cesarean section. ${ }^{28}$ In this study, only $51 \%$ of the patients had a history of at least 1 cesarean delivery, a data similar to the case series described by Leite et al, ${ }^{20}$ in which $30.3 \%$ of cases were of multiparous women.

There are few evaluations on how to prevent AWE. However, some suggestions were found: dislocation of the uterus outside the pelvic cavity for the performance of hysterotomy, the use of different suture needles and materials for the uterus and remaining cavity plans, irrigation with high-jet saline, avoiding the use of surgical sponges to clean the endometrial cavity in the intraoperative period, thorough cleaning of the abdominal cavity after hysterorrhaphy, attention while delivering the placenta to avoid spillage of uterine contents into the abdominal cavity, and protection of the surgical margins to prevent endometrial implants in the surgical incision. ${ }^{2,17,29}$

In the literature, there was no significant evidence that the clinical course of the patient was better with the use of hormones after surgery, which is in agreement with our study. It should be reinforced that if pelvic endometriosis persists, along with AWE, hormone therapy should be used to control the disease. ${ }^{24}$

In the present study, the precise relationship between cesarean section and AWE could not be established, despite the high rate of cesarean sections in patients with AWE.

A limitation of the study is its retrospective nature, which makes data collection and complete data acquisition more difficult. A prospective study has been suggested, in which data can be collected in a correct and detailed manner.

Although a large part of the data obtained in this project is consistent with the literature, the difference in the recurrence rate of AWE is notable. Studies have reported an average rate of $4.3-9.1 \%$ of disease relapse. In contrast, our study obtained a recurrence rate of $26.9 \%$. The discordant results can be explained by the fact that in a tertiary hospital we usually treat more complex and difficult cases. Another possible explanation is that, during surgery, care to isolate and exchange surgical fields and material, washing and drying the abdominal cavity, attention during hysterorrhaphy, and closure of the remaining planes may be ineffective in this hospital setting. In the university hospital, residents receive training and knowledge that will last for a lifetime, and the surgeries are not only performed by skilled specialists.

Endometriosis of the abdominal wall is not a highly prevalent disease in the population. However, it may lead to a great deal of discomfort, and impair the quality of life of women of reproductive age. Despite contrary results in the literature, the recurrence rate in our service was elevated. More caution and attention is required while operating patients with endometriosis, particularly when a hysterectomy has been performed. A prospective study should be performed to better evaluate the possible factors related to the disease for the improvement of patient care.

We conclude that women with previous cesarean sections with local pain or lumps should be investigated for AWE. The recurrence of AWE is high, especially when the first surgery is not appropriate and leaves compromised surgical margins.

Financial Disclosure/Conflicts of Interest

The authors declare no conflicts of interest.

\section{References}

1 Giudice LC, Kao LC. Endometriosis. Lancet 2004;364(9447):1789-1799

2 Bektaş H, Bilsel Y, Sari YS, et al. Abdominal wall endometrioma; a 10-year experience and brief review of the literature. J Surg Res 2010;164(01):e77-e81

3 Douglas C, Rotimi O. Extragenital endometriosis-a clinicopathological review of a Glasgow hospital experience with case illustrations. J Obstet Gynaecol 2004;24(07):804-808

4 Mascaretti G, Di Berardino C, Mastrocola N, Patacchiola F. Endometriosis: rare localizations in two cases. Clin Exp Obstet Gynecol 2007;34(02):123-125

5 Liu K, Zhang W, Liu S, Dong B, Liu Y. Hepatic endometriosis: a rare case and review of the literature. Eur J Med Res 2015;20:48 
6 Lee HJ, Park YM, Jee BC, Kim YB, Suh CS. Various anatomic locations of surgically proven endometriosis: A single-center experience. Obstet Gynecol Sci 2015;58(01):53-58

7 Badawy SZ, Shrestha P. Recurrent catamenial pneumothorax suggestive of pleural endometriosis. Case Rep Obstet Gynecol 2014;2014:756040

8 Huang H, Li C, Zarogoulidis P, et al. Endometriosis of the lung: report of a case and literature review. Eur J Med Res 2013;18:13

9 Mostafa HA, Saad JH, Nadeem Z, Alharbi F. Rectus abdominis endometriosis. A descriptive analysis of 10 cases concerning this rare occurrence. Saudi Med J 2013;34(10):1035-1042

10 Nezhat C, King LP, Paka C, Odegaard J, Beygui R. Bilateral thoracic endometriosis affecting the lung and diaphragm. JSLS 2012;16 (01):140-142

11 Veeraswamy A, Lewis M, Mann A, Kotikela S, Hajhosseini B, Nezhat C. Extragenital endometriosis. Clin Obstet Gynecol 2010;53(02): 449-466

12 Nominato NS, Prates LFVS, Lauar I, Morais J, Maia L, Geber S. Caesarean section greatly increases risk of scar endometriosis. Eur J Obstet Gynecol Reprod Biol 2010;152(01):83-85

13 Nominato NS, Prates LFVS, Lauar I, Morais J, Maia L, Geber S. [Scar endometriosis: a retrospective study of 72 patients]. Rev Bras Ginecol Obstet 2007;29(08):423-427 Portuguese

14 Sinha R, Kumar M, Matah M. Abdominal scar endometriosis after Caesarean section: a rare entity. Australas Med J 2011;4(01):60-62

15 Chang Y, Tsai EM, Long CY, Chen YH, Kay N. Abdominal wall endometriomas. J Reprod Med 2009;54(03):155-159

16 Papavramidis TS, Sapalidis K, Michalopoulos N, et al. Spontaneous abdominal wall endometriosis: a case report. Acta Chir Belg 2009; 109(06):778-781

17 Wasfie T, Gomez E, Seon S, Zado B. Abdominal wall endometrioma after cesarean section: a preventable complication. Int Surg 2002; 87(03):175-177

18 Sirito R, Puppo A, Centurioni MG, Gustavino C. Incisional hernia on the 5-mm trocar port site and subsequent wall endometriosis on the same site: a case report. Am J Obstet Gynecol 2005;193 (3 Pt 1):878-880

19 Rao R, Devalia H, Zaidi A. Post-caesarean incisional hernia or scar endometrioma? Surgeon 2006;4(01):55-56

20 Leite GKC, Carvalho LFP, Korkes H, Guazzelli TF, Kenj G, Viana AdeT. Scar endometrioma following obstetric surgical incisions: retrospective study on 33 cases and review of the literature. Sao Paulo Med J 2009;127(05):270-277

21 Ding Y, Zhu J. A retrospective review of abdominal wall endometriosis in Shanghai, China. Int J Gynaecol Obstet 2013;121(01): 41-44

22 Vilarino FL, Bianco B, Martins ACM, Christofolini DM, Barbosa CP. [Surgical scar endometriosis: a series of 42 patients]. Rev Bras Ginecol Obstet 2011;33(03):123-127 Portuguese

23 Ecker AM, Donnellan NM, Shepherd JP, Lee TT. Abdominal wall endometriosis: 12 years of experience at a large academic institution. Am J Obstet Gynecol 2014;211(04):363.e1-363.e5

24 Horton JD, Dezee KJ, Ahnfeldt EP, Wagner M. Abdominal wall endometriosis: a surgeon's perspective and review of 445 cases. Am J Surg 2008;196(02):207-212

25 Zhao X, Lang J, Leng J, Liu Z, Sun D, Zhu L. Abdominal wall endometriomas. Int J Gynaecol Obstet 2005;90(03):218-222

26 Akbulut S, Sevinc MM, Bakir S, Cakabay B, Sezgin A. Scar endometriosis in the abdominal wall: a predictable condition for experienced surgeons. Acta Chir Belg 2010;110(03):303-307

27 de Oliveira MA, de Leon ACP, Freire EC, de Oliveira HC. Risk factors for abdominal scar endometriosis after obstetric hysterotomies: a case-control study. Acta Obstet Gynecol Scand 2007;86(01): 73-80

28 Wicherek L, Klimek M, Skret-Magierlo J, et al. The obstetrical history in patients with Pfannenstiel scar endometriomas-an analysis of 81 patients. Gynecol Obstet Invest 2007;63(02):107-113

29 Nissotakis C, Zouros E, Revelos K, Sakorafas GH. Abdominal wall endometrioma: a case report and review of the literature. AORN J 2010;91(06):730-742, quiz 743-745 